\title{
Redes no território: experimentações de um programa de extensão entre desassossegos e regulamentações da vida
}

\author{
Networks in the territory: experiments with an extension program between \\ unrest and life regulations
}

Ana Lucia Coelho Heckert; Caíco Barbosa da Costa; Daniel Barros Bermudes; Isabelle Emerick da Rocha; Joyce dos Anjos Barcellos; Kaick Rocha Pereira; Leonardo Martins Roriz Rébuli; Mariana Ribeiro de Souza; Raiani Dercilia da Silva; Thamires Lemos Ferreira

Universidade Federal do Espírito Santo

\section{RESUMO:}

Este artigo visa compartilhar e colocar em análise um percurso de extensão e pesquisaintervenção trilhado, durante uma década no município de Cariacica/ES, por um Programa de Extensão e Pesquisa de uma universidade pública. Os objetivos das intervenções efetuadas consistiam em fomentar a produção de redes entre políticas públicas, e finalizou focalizando ações da juventude de periferia. Este artigo focaliza algumas das ações efetuadas no âmbito deste Programa de Extensão e Pesquisa nos últimos 04 anos, quando o foco do trabalho incidiu nas questões relativas à juventude negra da periferia, apontando a pesquisa intervenção como método de fazer pesquisa e extensão.

Palavras-chave: redes; Políticas Públicas; juventude

\begin{abstract}
:
This article aims to share and analyze a path of extension and research-intervention followed, during a decade in the municipality of Cariacica / ES, through an Extension and Research Program of a public university. The objectives of the interventions carried out consisted of promoting the production of networks between public policies, and ended with a focus on the actions of youth from the periphery. This article focuses on some of the actions carried out within the scope of this Extension and Research Program in the last 04 years, when the focus of the work was on issues related to black youth from the periphery, pointing out intervention research as a method of doing research and extension.
\end{abstract}

Key words: network; Public Policies; youth

DOI: 10.12957/mnemosine.2020.52689

\section{Introdução}

Neste artigo compartilhamos experiências de pesquisa-intervenção efetuadas no âmbito do Programa de Extensão e Pesquisa Redes de Políticas no Território: políticas públicas e movimentações sociais que realizamos desde 2009 no município de 
162 Ana Lucia Coelho Heckert; Caíco Barbosa da Costa; Daniel Barros Bermudes; Isabelle Emerick da Rocha; Joyce dos Anjos Barcellos; Kaick Rocha Pereira; Leonardo Martins Roriz Rébuli; Mariana Ribeiro de Souza; Raiani Dercilia da Silva; Thamires Lemos Ferreira.

Cariacica/ES. O programa atuou no período de agosto de 2009 a março de 2020, e objetivou, ao longo desses anos, apoiar e fortalecer a interlocução entre políticas públicas no município de Cariacica. Nos últimos 4 anos se aproximou dos movimentos sociais e dos coletivos informais de juventude que se organizam com o intuito de transformar a realidade do município de Cariacica/Espírito Santo, no que se refere ao acesso às políticas públicas. As ações do Programa incluíram conexões com jovens participantes destes movimentos/coletivos, profissionais que atuam em equipamentos públicos de saúde, educação e assistência social, além de parceria com uma Rede de Cursinhos Populares Pré-ENEM. Um outro eixo do Programa de Extensão abarcou pesquisa com estudantes que participaram do processo de luta contra o fechamento de escolas estaduais, que começou a ocorrer em 2015. Nossa inquietação era que as políticas públicas já existentes no município, e voltadas à juventude, fossem efetivadas de modo a afirmar o protagonismo da juventude na luta por direitos sociais e na gestão das políticas públicas. Além desta ação de conversação com os coletivos de juventude e com movimentações de lutas por escola, seja nos movimentos de ocupação de escola ocorridos em 2016, seja nas ações de luta dos estudantes contra o fechamento de unidades escolares estaduais efetuadas em $2018^{1}$, apoiamos também a organização e a realização do I e II Ocupa Afirmação Rede de Cursinhos populares pré-ENEM, evento realizado no campus de Goiabeiras da UFES (Universidade Federal do Espírito Santo).

A continuidade deste Programa de Extensão por uma década se efetuou em função de seu modo de funcionamento, bem como das demandas e conexões efetuadas no território. Neste artigo focalizaremos parte das ações que efetuamos, destacando intervenções realizadas nos últimos 4 anos e que integraram as ações com os coletivos de juventude e com o Rede Afirmação. Iniciamos apresentando o funcionamento do Programa para, na sequência, compartilharmos as últimas ações efetuadas.

\section{O funcionamento do Programa de Extensão como experimentação da pesquisa intervenção: algumas ferramentas de nossas caixas}

O Programa de Extensão Redes no Território foi criado em 2009, a partir de uma proposição que congregou estudantes de graduação em psicologia, 01 mestrando do Programa de Pós-Graduação em Psicologia Institucional (PPGPSI) e 01 professora do Departamento de Psicologia da universidade. Uma disciplina optativa era campo de Estágio em Docência para 02 mestrandos do PPGPSI, discutindo produção de redes entre 
políticas públicas. Ao término da disciplina, 05 estudantes de graduação propuseram a um dos mestrandos a criação de um projeto de extensão para que pudessem experimentar os debates que haviam sido efetuados ${ }^{2}$.

Nossa caixa de ferramentas incluía os aportes da Análise Institucional (LOURAU, 1993) com as formulações da pesquisa intervenção elaboradas principalmente no Brasil ${ }^{3}$ (ROCHA et al., 2003; PAULON, 2005), as formulações de Foucault (2005, 2007 e 2009), e, mais atualmente, a extensa produção acerca das relações étnico-raciais no Brasil (NASCIMENTO, 2017; BENTO, 2002; SANTOS, 2014), além das formulações de autores como Fanon (1979 e 2008) e Mbembe (2018a; 2018b).

A perspectiva que pautou nosso método de trabalho foi a pesquisa-intervenção. Nosso desafio ao atuarmos com esse método foi efetuar modos de produção do saber que não se dissociassem dos processos de intervenção, assim como delinear um campo problemático disparador de temáticas e problemas conectados à complexidade dos processos que hoje forjam as demandas e propostas dos jovens que habitam as periferias e as políticas públicas no Brasil. Entendemos o método como modo de fazer pesquisa e extensão que não se dissocia de seus princípios e campo problemático (HECKERT et al., 2009). O campo problemático, ao mesmo tempo em que dispara os processos de extensãopesquisa e solicita a definição das estratégias que serão utilizadas no acompanhamento dos processos, é reformulado e delineado no próprio fazer do trabalho, alterando a formulação do que é delineado como problema/foco de trabalho. O que estamos denominando campo problemático não reside no delineamento de questões/problemas, $a$ priori, para as quais se busca encontrar a solução ou confirmar sua veracidade. Conforme afirmou Deleuze (1999: 10), a verdade ou falsidade de um problema não se situa na possibilidade ou não de sua resolução.

Partilhamos do paradigma institucionalista ao postular que toda produção de saber é necessariamente intervenção: produz realidades, institui práticas, interfere produzindo movimentos (LOURAU, 2004a, 2004b). Trata-se mais de um aprender-fazendo do que de um aprender para fazer. A pesquisa intervenção visa à interrogação das práticas naturalizadas e materializadas nas práticas sociais, colocando em análise as instituições em cena em determinado campo. A intervenção implica o delineamento de um campo de intervenção e um campo de análise que são indissociáveis, porém distintos ${ }^{4}$.

A pesquisa intervenção visa ampliar graus de transversalidade (índice de comunicação inter e intra grupos), por meio da análise das práticas em ação (GUATTARI, 
164 Ana Lucia Coelho Heckert; Caíco Barbosa da Costa; Daniel Barros Bermudes; Isabelle Emerick da Rocha; Joyce dos Anjos Barcellos; Kaick Rocha Pereira; Leonardo Martins Roriz Rébuli; Mariana Ribeiro de Souza; Raiani Dercilia da Silva; Thamires Lemos Ferreira.

1981). No campo das ciências humanas, ainda vigora uma compreensão "aplicacionista" que percorre os processos de formação e de pesquisa, pautados pelo princípio de que conhecemos para transformar, produzimos conhecimentos a serem aplicados a uma suposta realidade já dada. É o ideal de inteligibilidade de que o conhecer antecede o fazer, garantindo-se assim a suposta neutralidade e imparcialidade do conhecimento.

O trabalho de pesquisa que efetuamos pretendeu também se constituir como um dispositivo de interpelação das políticas de regulamentação da vida que têm silenciado as lutas pela construção de políticas públicas em nosso país, lutas que interferem no processo de sucateamento da vida. Entendemos que as interferências protagonizadas pela juventude têm colocado em análise principalmente este funcionamento fragmentado e regulamentador da vida por parte das políticas sociais.

Buscamos efetuar as intervenções de modo que os procedimentos metodológicos usados afirmassem um processo participativo de produção de dados, subsidiando decisões e movimentos considerados pertinentes e prioritários pelos jovens. Nesta perspectiva, buscamos que os jovens fossem menos objeto de coleta de dados e/ou de intervenção, e muito mais sujeitos produtores de análise acerca de suas demandas, do funcionamento e gestão das políticas públicas, das movimentações que efetuam.

O Programa realizava, no início do período letivo, atividades de avaliação de suas ações previstas e o planejamento coletivo das mesmas. Neste planejamento, definíamos o foco de nossas ações e os eixos que pautariam as atividades a serem realizadas. $\mathrm{O}$ programa congregou, além das ações de extensão, ações de formação dos estudantes de psicologia e projetos de pesquisa que emergiam das questões vivenciadas na extensão. Inicialmente, quando foi criado, o Redes teve como foco de trabalho a produção de redes entre políticas de assistência social, educação e saúde. Posteriormente, este foco foi alterado em decorrência das análises que fazíamos dos movimentos no território. A partir de 2014, o Programa de Extensão passou a lidar intensamente com as questões relativas à juventude de periferia. Com isso, as movimentações destes grupos se tornaram foco das ações de extensão e pesquisa que realizávamos.

As estratégias metodológicas que utilizamos nas intervenções incluíram: realização de rodas de conversa voltadas aos movimentos de juventude e/ou coletivos que incluíssem jovens, visando construir estratégias coletivas de ação voltadas à ampliação do acesso às políticas públicas por este segmento; restituição aos participantes da análise 
dos dados formuladas no processo de produção de dados acerca dos movimentos e coletivos de juventude em ação no município de Cariacica; fomento à criação de grêmios estudantis e outras formas de organização que incrementassem a participação dos jovens da gestão das políticas públicas. Também a produção de materiais informacionais (fanzines, folders, cartilhas, etc.) visando compartilhar ações relativas ao âmbito de atuação do projeto e o fomento à criação de fóruns de debates acerca da questão 'juventude e políticas públicas'. Os grupos com os quais trabalhamos abrangeram jovens que residem no município de Cariacica, participantes de movimentos ou coletivos que efetuassem ações voltadas à produção de uma vida digna, enfrentando processos de precarização da vida; e incluíram também profissionais que atuavam nas políticas sociais.

Desde que o Redes foi criado, em 2009, sempre tivemos uma atenção especial para a produção de grupalidade entre os participantes do projeto. Esta produção de grupalidade abarcava uma série de ações que efetuamos, além de uma escuta que tentava estar atenta ao que se passa na vida dos extensionistas no curso. Assim é que partilhamos experiências de racismo, de machismo, de lgbtfobia dentro e fora da UFES. Partilhamos também as experiências de como é a vida de estudantes de graduação da periferia. Quando os extensionistas se inseriam no REDES, recebiam o Kit Redes com os projetos de extensão e de pesquisa, os relatórios dos projetos e a carta de princípio do Redes que abaixo reproduzimos. Semanalmente, nossas reuniões iniciavam com um café-da-manhã que partilhávamos. Tivemos, ao longo destes 10 anos, vários cadernos de atas em que fazíamos nossa pauta e registrávamos as principais pactuações feitas. A cada reunião, 01 extensionista assumia a produção desta ata. Na verdade, era menos uma ata e mais um caderno que registrava as memórias intensivas e extensivas ${ }^{5}$ do que vivíamos e construíamos juntos. A cada aniversário de um integrante, tínhamos um bolo e um café mais especial, e uma foto com o grupo. Ao final do percurso na graduação, quem tinha participado do Programa Redes recebia em sua colação de grau uma caixinha com poesias, fotos no Redes, bombons e um livro, que se tornou a famosa "caixinha do REDES".

Nossas supervisões eram momentos de trocar informes do curso, da vida, das ações do programa e de definir pactuações e responsabilidades. Os acordos feitos e não efetuados, os incômodos e as indagações eram levadas para o grupo, visando um exercício de desindividualização e de análise coletiva dos processos experimentados, colocando em análise processos de implicação e de sobreimplicação ${ }^{6}$. Cada membro do grupo tinha 
166 Ana Lucia Coelho Heckert; Caíco Barbosa da Costa; Daniel Barros Bermudes; Isabelle Emerick da Rocha; Joyce dos Anjos Barcellos; Kaick Rocha Pereira; Leonardo Martins Roriz Rébuli; Mariana Ribeiro de Souza; Raiani Dercilia da Silva; Thamires Lemos Ferreira.

também como compromisso a responsabilidade ético-política de colocar na roda demandas e propostas que recebíamos.

A seleção para participar como extensionista sempre foi aberta. Enviávamos informes por meio do colegiado de curso sobre data e local da seleção, além de cartazes e divulgação nas redes sociais. Os candidatos eram convidados a participar de uma reunião do Programa e a responder em grupo algumas questões. Após esta conversa, coordenação e extensionistas debatiam acerca da conversa com os candidatos e indicavam os nomes que poderiam compor o grupo. A coordenação assumia a responsabilidade pela escolha final dos novos participantes e comunicava o resultado.

Em função do foco do programa de extensão e das questões partilhadas em nosso cotidiano, fomos nos tornando cada vez mais um Programa de Extensão com participação majoritária de estudantes negros. Também em função desse arranjo fomos assumindo mais ações e debates que envolviam a questão do racismo, da branquitude e das estratégias de resistência da população negra que vive em nossas periferias. Muitos de nossos ex-extensionistas atuam como psicólogos em políticas públicas em vários municípios do Espírito Santo.

Por esta atuação também é que fomos convidados a apoiar as atividades de organização e execução do I e II OcupaAfirmação. O Afirmação (Rede de Cursinhos Populares pré-Enem) ${ }^{7}$ é um grupo que oferta, desde 2017, aulas de preparação para o Enem em 05 polos da Grande Vitória/ES (Serra, Vitória, Viana, Vila Velha e Cariacica), visando ampliar o acesso dos jovens de periferia à universidade pública. Nos anos de 2018 e 2019, o Afirmação fez uma parceria com o nosso Programa de Extensão, que consistiu na realização de uma visita técnica dos estudantes e equipe de coordenação à universidade. Nesta visita foram ofertadas atividades durante a tarde de um sábado para os estudantes vinculados a esta entidade. Estas atividades consistiram de palestras acerca das políticas afirmativas para acesso e permanência na universidade pública, exposição de filmes de curta metragem, oficinas temáticas, lanche, etc. Os objetivos destas atividades do OcupaAfirmação foram de oportunizar aos estudantes desta rede a aproximação com o território da UFES, efetuar debates acerca das políticas afirmativas no Brasil, além de discutir temas de interesse dos estudantes e da coordenação desta rede de cursinhos. 


\section{Princípios do Programa de Extensão e Pesquisa}

Inspirados no prefácio que Foucault (1991) elaborou para o livro O anti-Édipo de Deleuze e Guattari, formulamos os 08 princípios que pautaram nossa trajetória. Esta carta de princípios era partilhada com todos os extensionistas que se inseriam no Programa. Reproduzimos aqui estes princípios por terem sido uma das ferramentas que usamos na produção de grupalidade e de campos de análise do Programa.

O Redes tem como princípio uma aposta nas políticas públicas como campo de criação de possíveis para as vidas que são "deixadas para morrer", nos dizeres de Foucault (2009). Ou seja, nossas ações visavam a produção de vidas dignas, e políticas aliançadas com as forças do coletivo que se efetivem como públicas. O segundo princípio que mobilizava as ações do Redes é de que o isolamento e a fragmentação do processo de trabalho fragilizam as ações nos serviços. Sendo assim, o fortalecimento das vias de comunicação existentes, bem como a produção de novas conexões entre políticas públicas, e também dessas políticas com o território (pensado como efeito impermanente dos usos dos atores no espaço), podem se constituir como operadores na construção e fortalecimento das redes que sustentam as vidas geridas nos territórios de Cariacica. Nosso terceiro princípio é o de que Cariacica não é o lugar de toda miséria. Nem Cariacica e nem nenhum outro lugar está fadado à produção de modos de vida precarizados. Nosso prisma é de uma oposição sistemática às "políticas de pobre para pobre", às ações reacionárias que mantêm o status quo da miséria que alimenta o neoliberalismo, ao isolamento que empobrece a vida em seus mais diversos aspectos. E ao caráter aplicacionista do conhecimento em que vamos aos territórios aplicar o que aprendemos ou verificar as mazelas do mundo, sem exercitar uma diretriz ético-política de interferir no amesquinhamento da vida. O quarto princípio enuncia que as questões produzidas no território deveriam ser analisadas em supervisão. A análise era pensada por nós em consonância com o paradigma institucionalista, ou seja, como exercício coletivo de produção de sentidos em meio aos jogos de forças que nos atravessam e constituem (LOURAU, 1993). Esse princípio permitia encontrar e inventar saídas para não reproduzirmos o que se atualiza no território como mortificação, fragmentação, paralisia, etc., além de ensejar possibilidades de intervenção embasadas nos demais princípios. $\mathrm{O}$ quinto princípio entende que não há como produzir ou fortalecer redes se não realizarmos o esforço para produzi-las entre nós. E rede não é pensada aqui como um conjunto de pessoas juntas pensando igual, a rede tem um caráter conectivo e também heterogenético 
168 Ana Lucia Coelho Heckert; Caíco Barbosa da Costa; Daniel Barros Bermudes; Isabelle Emerick da Rocha; Joyce dos Anjos Barcellos; Kaick Rocha Pereira; Leonardo Martins Roriz Rébuli; Mariana Ribeiro de Souza; Raiani Dercilia da Silva; Thamires Lemos Ferreira.

(KASTRUP, 2000). Não é produção de homogeneidade, mas produção que ganha sentido e velocidade na conexão que amplia as multiplicidades à medida em que se conecta e faz diferir a própria rede. O nosso sexto princípio indica que se falamos redes isso implica processos compartilhados de gestão do projeto em que cada um é sujeito produtor desta história-redes, implicado com seus tensionamentos e construções, com a produção de grupalidade e com os compromissos que o programa assume. Isso incluía exercitar a regra do tudo dizer da análise institucional, visando fiar junto (con-fiar) as apostas, as derrapadas e os desvios necessários à continuidade do projeto, sem descuidar da análise de nossas implicações e sobreimplicações. O sétimo princípio apontava que o Redes era um Programa de Extensão e Pesquisa que tinha como desafio experimentar o princípio institucionalista de que transformamos para conhecer e de que a gênese social caminha junto com a gênese teórica. Por fim, o oitavo princípio: seguir a regra da micropolítica de Foucault (1991) de não atrapalhar os processos, os devires, as invenções da vida e não se apaixonar pelo poder.

\section{O território de Cariacica e suas lutas}

Cabe salientar que a maioria de nossas intervenções foi realizada no território de Cariacica, território esse que é efeito de processos de implementação de políticas que se deram permeados por iniquidade e por lutas de afirmação da vida. Entendemos, a partir das contribuições de Milton Santos (2004), o território como um espaço relacional, usado, demarcado pela provisoriedade de seus contornos e arranjos políticos, sociais, econômicos e culturais. O território é expressão de relações de poder-saber e resistência, dos modos de organização e distribuição (desigual) da riqueza socialmente construída.

Os estudos de Silva (2004) permitem perceber que o modo de gestão das políticas públicas no Estado do Espírito Santo operou de forma a alijar grandes parcelas da população do acesso às políticas públicas, ou ainda, de imprimir um acesso desigual a estas mesmas políticas. De acordo com a autora, o Espírito Santo efetuou um processo de modernização econômica que não foi acompanhado de mudanças nas relações políticas e institucionais. Este cenário trazia e traz ainda extremas dificuldades para a continuidade e implementação de políticas públicas. O quadro de iniquidade com relação ao acesso e qualidade das políticas públicas ofertadas, bem como a verticalização dos processos de gestão ainda é intenso. 
Cariacica faz parte da Região Metropolitana da Grande Vitória, é um dos municípios mais populosos do Espírito Santo e passa por graves problemas de exclusão social. Tem uma população registrada em 2010 pelo IBGE de 348.738 mil habitantes e a estimativa em 2019 foi de 381.285 habitantes. Mattos (2011) aponta que Cariacica passou por um aumento populacional muito expressivo da década de 1960 até os anos 2000, de praticamente $1000 \%$. Um processo que ocorreu de forma desordenada, culminando na formação de regiões com intensos problemas de precarização, como miséria, baixa escolaridade, baixa qualificação profissional e poder aquisitivo e desemprego, dentre outros. Entre as influências para esse verdadeiro boom populacional estão a proximidade com Vitória, a implementação de grandes projetos industriais a partir de década de 1970 no Espírito Santo, e especificamente na região da Grande Vitória, como as usinas de Tubarão, a Belgo Mineira e a de pelotização da Companhia Vale do Rio Doce, com as duas primeiras formando atualmente o complexo da Arcelor Mittal, donde decorre um fluxo de imigrantes em busca de melhores condições de vida.

Como aponta Oliveira (2019: 37), a partir da década de 1970 ocorreu uma intensa desaceleração industrial no município, e, assim, parte do contingente populacional que atuava nesta esfera produtiva foi absorvida em outros setores da economia local, por meio do setor de serviços. Outra parte passou a trabalhar em outros municípios da Grande Vitória, retornando para suas residências após a jornada de trabalho. Por esse motivo, Cariacica se tornou conhecida como município dormitório.

Segundo dados do IBGE de 2010, quase 1/3 da população de Cariacica era composta por jovens de 15 a 29 anos. Em 2011, a população jovem chegou a 63.565 pessoas, sendo que, destes jovens, 69\% são negros. Em 2019, Cariacica ocupou o $56^{\circ}$ lugar dentre os municípios com maiores taxas de homicídio do país. De acordo com o Mapa da Violência de 2013, os homicídios são, hoje, a principal causa de morte de jovens de 15 a 24 anos no país e atingem especialmente jovens negros do sexo masculino, moradores das periferias e áreas metropolitanas dos centros urbanos" (WAISELFISZ, 2013).

Esses processos foram a cada dia se tornando mais presentes nas intervenções que fazíamos, debatendo as conexões entre as políticas sociais em Cariacica. As movimentações da população pelo exercício do direito aos direitos sociais em muitas situações se fazem por meio de ações locais e descontínuas, fragmentadas e imprevisíveis. São pouco valorizadas como ações potentes por não corresponderem aos padrões 
170 Ana Lucia Coelho Heckert; Caíco Barbosa da Costa; Daniel Barros Bermudes; Isabelle Emerick da Rocha; Joyce dos Anjos Barcellos; Kaick Rocha Pereira; Leonardo Martins Roriz Rébuli; Mariana Ribeiro de Souza; Raiani Dercilia da Silva; Thamires Lemos Ferreira.

instituídos de organização e movimento social. Ainda que a população empreenda diversas ações para garantir seu direito de acesso à escola pública, aos serviços de saúde e de assistência social e, com isso, interfira nos rumos das políticas governamentais, corre-se o risco de apenas ganharem visibilidade as ações governamentais, muitas delas permeadas por práticas populistas e clientelistas.

Por isso, cabe ressaltar que os equipamentos públicos existentes em Cariacica, os avanços na melhoria nas condições de infraestrutura urbana, dentre outras questões, são frutos de muitas lutas da população que reside neste município. Se a história de precarização das condições de vida é intensa e extensa, não menos intensa e potente é a ação dos diversos movimentos sociais e coletivos nesta cidade.

Ao mesmo tempo, chamava nossa atenção certo modo como vem se hegemonizando a interlocução entre a escola e as políticas sociais, sendo para nós analisadora da forma como estão sendo acolhidas as demandas dos sujeitos que habitam nossas periferias. Analisador tem, aqui, o sentido conferido na Análise Institucional, ou seja, qualquer evento/acontecimento que coloca em cena as instituições que atravessam um campo de intervenção, permitindo que efetuemos a análise dos efeitos de tal atravessamento (LOURAU, 1993).

O que pudemos perceber é que a interlocução entre políticas sociais tem sido utilizada em muitas situações para efetuar uma espécie de encarceramento a céu aberto, como pontua Passetti (2004). Nosso desafio é fazer com que as conexões entre políticas públicas produzam vidas dignas e que se efetuem como estratégia de conversação, de compartilhamento de experiências, em lugar de se configurarem como instrumento de controle. $\mathrm{O}$ direito à educação não se operacionaliza sem a conexão com os demais direitos sociais. E é na interface entre políticas públicas, na ampliação da comunicação da escola com os equipamentos sociais existentes em dado território, que é possível deslocar a escola e os equipamentos de assistência social e de saúde do lugar em que vêm sendo colocados, ou seja, de gestores da miséria necessária (OLIVEIRA, 2010). Esta interlocução tem sido muitas vezes acionada como modo de ampliação do controle da vida de crianças, jovens e de suas famílias. Portanto, torna-se necessário criar outros possíveis que funcionem de modo a ampliar a vida, pois as políticas sociais tanto se constituem como estratégia de regulamentação da vida quanto podem funcionar para enfrentar o sucateamento da existência. 
Porém ainda lidamos com índices reduzidos de transversalização das práticas e com esquadrinhamentos que colocam um equipamento em cada lugar/função. As conexões efetuadas ainda não conseguiram reverter de forma expressiva os modos de trabalho fragmentados e as práticas verticalizadas de gestão. Nossos projetos de pesquisa focalizaram o estudo dos processos de regulamentação da vida em curso e as interferências das movimentações sociais nos modos de operar as políticas públicas. Nosso campo de pesquisa e de intervenção ficou atento aos canais formais e informais de participação na gestão das políticas de educação, saúde e assistência social e as ações dos movimentos comunitários institucionalizados e não institucionalizados no tocante à implementação de tais políticas.

A aproximação com as demandas e problemáticas vivenciadas pela juventude no estado do Espírito Santo se deu com a realização de projetos de pesquisa-intervenção no Município de Cariacica no período de 2004 a 2009 e, posteriormente, desde 2009, com a criação de projetos de extensão e de pesquisa que focalizam este segmento. Foi a partir da aproximação com o cotidiano de vida da população, com o acompanhamento das ações realizadas nos equipamentos sociais deste município que percebemos a importância de debater as políticas públicas voltadas à juventude. No projeto de extensão em andamento sob nossa coordenação, iniciamos ações voltadas ao fortalecimento da participação dos estudantes na gestão da escola pública, por meio de sua vinculação aos conselhos de escola e da criação de grêmios estudantis. A atuação que efetivamos junto ao Centro de Referência da Assistência Social (CRAS), notadamente com o PROJOVEM, e o trabalho que iniciamos junto aos movimentos comunitários desta região também apontou para a diversidade de demandas dos jovens que vivem nas regiões de periferia e os desafios que lidam no cotidiano de suas vidas.

O Estado, com suas políticas de segurança genocidas, tem corroborado com o extermínio principalmente dos jovens negros. Para além da tentativa que tem sido feita de descrédito com relação à juventude no Brasil - como, por exemplo, os constantes debates com relação à redução da maioridade penal -, percebemos uma potência nestes jovens que precisa ser afirmada. Nossas experiências mostram que o fortalecimento do convívio entre estes jovens tem sido de fundamental importância para a formação de suas intervenções políticas. De acordo com Castro (2008), a juventude produz diferentes modalidades de ação com o intuito de transformação social. Nesse sentido, podemos dizer que há uma falsa afirmação quando se diz que a 'juventude é apática politicamente', pois 
há jovens em diferentes cantos, inclusive em Cariacica/ES, construindo estratégias de enfrentamento da dura realidade vivenciada e de transformação social. O que parece existir entre os jovens é uma descrença no fazer político tradicional, em seu modelo representativo, em especial nas instituições. Isso não significa, porém, que essa juventude seja despolitizada; há que se indagar quais políticas pretendem afirmar em suas vidas e quais destas políticas visam rechaçar.

Nossas intervenções indicam que não existem, no município de Cariacica, políticas públicas formuladas em conexão com a juventude, ouvindo suas demandas. Mas existem muitos movimentos jovens e ações de participação efetuando-se nos dispositivos formais de co-gestão de políticas públicas e também como ações informais. Em um momento no qual a juventude vem sendo constantemente marginalizada e alvo de processos de criminalização e desqualificação, diversos jovens vêm se movimentando e se organizando na busca de melhores condições de vida e visando enfrentar as práticas de racismo com que lidam cotidianamente.

\section{As movimentações da juventude}

Há mais de duas décadas que pesquisas educacionais indagam o modo como as políticas de educação vêm sendo construídas e geridas pelo aparelho estatal (HECKERT, 2004), em que os usuários são tratados como meros destinatários das ações governamentais. As políticas estatais pouco dialogam com as experiências concretas de profissionais, crianças e jovens, homens e mulheres que criam cotidianamente estratégias para fazer valer ou inventar direitos sociais. As políticas estatais dizem falar em nome dos sujeitos, sobre os sujeitos de sua ação, e o que vemos é uma reduzida interlocução com os sujeitos concretos com suas experiências e demandas.

Entendemos que somente a implementação de políticas públicas não garante a efetividade das mesmas, nem tampouco poderá dar conta das necessidades da população. Não podemos deixar de mencionar que a efetividade das políticas estatais tem se vinculado a regulamentar a vida dos jovens da periferia. Apostamos na relação entre políticas públicas, equipamentos e usuários e na ampliação da comunicação dessas políticas em rede, conforme já explicitado anteriormente, no intuito de afirmar modos de vida que escapem à sua regulamentação. Por isso tivemos uma atenção maior para as ações sociais formais e informais organizadas por jovens no município. Buscamos nessa 
esfera o público jovem que se encontra para lutar por melhorias de vida ou para afirmar formas de resistir às dificuldades da realidade que vivenciam, seja realizando atividades numa praça pública ou se organizando por movimentos sociais institucionalizados ou não.

Entretanto, cabe esclarecer de qual perspectiva partimos quando falamos de juventude. A existência de uma suposta natureza da juventude consolidou-se no século XX e, de acordo com alguns autores, como Coimbra e Nascimento (2005), a partir de certo modelo biomédico de pensar a adolescência e a juventude, pautado em perspectivas universalizantes e homogêneas. Além dos atributos comportamentais e fisiológicos, conexões entre a noção de periculosidade e pobreza contribuem no sentido de produzir o jovem pobre como potencialmente perigoso e em situação de risco social. O modo de expressão da juventude é efeito do entrecruzamento de processos históricos, políticos e econômicos. Por ser uma produção social, demanda atenção às suas variações. Mas as indagações enunciadas pelos jovens lidam com processos de silenciamento ou são desqualificadas como irracionais e ingênuas. O que ainda presenciamos é a produção de juventudes desiguais (COIMBRA et al., 2005).

O foco na construção de políticas públicas voltadas à juventude está relacionado à chamada 'onda jovem' ocorrida nos anos de 1990, com o grande crescimento populacional na faixa etária entre 15 e 24 anos (CORDEIRO, 2009). Autores como Novaes (2008: 126) apontam que "essa onda é vista no Brasil como um risco: risco de marginalidade, de violência, risco de risco". Ou seja, quando a juventude é tomada como um perigo biopolítico (FOUCAULT, 2009), vemos que o Estado se volta especialmente para este grupo, formulando ações que visam mitigar supostos riscos. O aumento populacional deste grupo e o quadro de intensas desigualdades sociais e dificuldades de acesso às políticas sociais compõem este cenário biopolítico, que faz viver e deixar morrer modos de vida. Especialmente podemos destacar o modo como as políticas públicas voltadas a este segmento ainda são efetuadas. Os jovens ainda são abordados como caso de polícia, ou seja, foco expressivo de políticas de segurança pública, em detrimento de políticas sociais tecidas em diálogo com estes sujeitos. Visa-se muito mais controlar a suposta delinquência juvenil, regulamentar suas vidas, gerir riscos e vulnerabilidades, integrar aos padrões de vida instituídos do que, de fato, fazer uma escuta atenta às suas apostas e projetos.

O que vemos em ação são políticas compensatórias direcionadas a manter certa estabilidade social, mas que não dialogam com os jovens. Ou, ainda, presenciamos a partir 
174 Ana Lucia Coelho Heckert; Caíco Barbosa da Costa; Daniel Barros Bermudes; Isabelle Emerick da Rocha; Joyce dos Anjos Barcellos; Kaick Rocha Pereira; Leonardo Martins Roriz Rébuli; Mariana Ribeiro de Souza; Raiani Dercilia da Silva; Thamires Lemos Ferreira.

dos anos 90 o incremento de políticas voltadas à inserção dos jovens no mundo do trabalho, em que os jovens são objetificados como capital humano a ser investido. Fraga e Iulianelli (2003: 12), analisando o foco das políticas voltadas à juventude, apontam:

A principal preocupação que alimenta as políticas públicas destinadas à juventude é prevenir e eliminar a violência, mas sempre segundo a perspectiva da segurança pública, como se a única questão de direitos humanos tivesse de passar pelo crivo da prestação de segurança. Essa atitude governamental também inspira uma série de organizações não-governamentais, muitas vezes centradas apenas na ideia da profissionalização, e não na perspectiva de promover novos espaços de sociabilidade e de convivio entre os jovens. Parece, entretanto, haver um equívoco nessa estratégia.

Pari passu a este processo, intensificaram-se ações coletivas protagonizadas por jovens, na esfera cultural, na apropriação de espaços da cidade para lazer e esporte, no âmbito das artes (música, literatura, cinema, etc). Assim, assistimos a emergência de diversos coletivos protagonizados por jovens como forma de expressar suas demandas.

Em nossas aproximações com as expressões da juventude em Cariacica, elaboramos uma cartografia que visou acompanhar os coletivos de juventude no território em que estão situados. Objetivávamos ampliar as conexões entre estes grupos. Conseguimos acessar 20 coletivos de juventude atuando em Cariacica/ES: Aprender Cultura, Um Ollie Para o Futuro, CineClube Colorado, Movimento Funk Capixaba, Escoteiros Loren Reno, Banda de Congo de Roda d'Água, Literatura MarginalES, Projeto Boca-a-Boca, Skatistas de Campo Grande, Skatistas de Santana, Viva Rima, CriAtividade, Casa do Estudante de Cariacica, HHMC, Liga Produções, Centro Nova Geração, Movimento da Juventude Rural, Adesjovem, Punks de Cariacica e Capoeira Brasil.

\section{Quando nossos fracassos mudam os rumos da intervenção}

Buscamos estreitar nosso diálogo com alguns destes coletivos para conhecer seu funcionamento e suas proposições. Dos 20 coletivos atuantes em Cariacica, foi possível ter uma aproximação maior com alguns destes. Depois de conversar com cada grupo, agendamos uma reunião com data, horário e local estabelecido pelos próprios grupos. Confirmamos presença na semana do encontro, compramos lanche e nos preparamos para uma primeira restituição acerca dos movimentos de juventude em Cariacica.

Chegamos ao local agendado e apenas nosso grupo de pesquisa e um jovem militante de direitos humanos e de fóruns de juventude compareceu. De início não 
entendemos o que se passou. Depois de muitas análises e indagações, fomos percebendo que este encontro era uma demanda do nosso projeto e que as redes que pensávamos existir se colocavam de outro modo. Os coletivos competiam entre eles e não entendiam os motivos pelos quais o nosso Programa Redes os convidava para uma conversa. A demanda em produzir conexões entre eles era nossa e precisava ser problematizada. $\mathrm{O}$ analisador devolutiva colocava em análise as práticas de produção de saber da academia, colocava em análise a distância entre a rotina do calendário universitário e o cotidiano dos coletivos. Uma relação de confiança não tinha sido tecida ainda: iriam ao nosso encontro para que?

Mudamos os rumos e recomeçamos as conversas: precisávamos de fato nos aproximar das ações e questões que estes jovens vivenciavam. Assim, alguns extensionistas incrementaram a participação nas atividades feitas pelos coletivos e começamos a conversar sobre como o Redes poderia contribuir com as ações deles. Ao mesmo tempo, começamos a nos dedicar mais intensamente a debates como os efeitos do racismo, a violência contra a mulher, a criminalização da juventude, o extermínio da juventude negra, dentre outros processos duros e necessários de serem debatidos.

Nas atividades que fazíamos dentro da universidade, começamos a chamar os coletivos para coordenar oficinas de rimas, de rap, dentre outras, dirigidas ao público universitário. Debates acerca do fechamento da academia aos jovens da periferia foram se expandindo. Nas idas à universidade, muitos acordos eram feitos. "O segurança da UFES não vai nos dar batida?" “Tem certeza? Vai ser de boa?” A maioria dos integrantes dos coletivos é de jovens negros, sabem muito bem como operam as políticas de segurança e que, historicamente, a universidade não é um espaço aberto aos negros.

Neste processo nos aproximamos de um jovem e uma jovem que faziam parte de um coletivo que faz e fala poesias nos ônibus da Grande Vitória ${ }^{8}$. Convidamos a dupla para fazer uma oficina para os extensionistas sobre produção de zines e nos prestar assessoria nesta ação com os coletivos de juventude. Nosso intuito era fazer um zine que registrasse as ações de alguns dos coletivos de juventude de Cariacica. Depois de oficinar com nossos mestres de Fanzine, propusemos aos coletivos com que conseguimos efetuar uma maior aproximação a produção de um zine que registrasse suas existências. Como há um processo de desqualificação imensa de Cariacica, colocando este município como espaço de mortificação e violência, a produção cultural dos jovens desta cidade não ganha 
176 Ana Lucia Coelho Heckert; Caíco Barbosa da Costa; Daniel Barros Bermudes; Isabelle Emerick da Rocha; Joyce dos Anjos Barcellos; Kaick Rocha Pereira; Leonardo Martins Roriz Rébuli; Mariana Ribeiro de Souza; Raiani Dercilia da Silva; Thamires Lemos Ferreira.

lugar. Consideramos que afirmar suas existências poderia ser uma estratégia potente de fortalecimento desses grupos.

A proposta de fabricação do Zine foi aceita por 05 grupos e depois de 02 anos de conversação com alguns coletivos de juventude e de 04 reuniões realizadas com os coletivos para organizar o material, conseguimos que fosse produzido o zine "Movimentações dos coletivos de juventude de Cariacica". O zine é uma coletânea que narra as ações de alguns coletivos de Cariacica/ES. O objetivo desta produção é dar visibilidade a estas ações e produzir contágios para que novos coletivos de juventude se integrem a este Zine. A produção foi publicada na página da Pró-Reitoria de Extensão da UFES no sítio da universidade ${ }^{9}$ e contou com a participação dos coletivos Aprender Cultura, Criatividade, Griôs Periféricos, Rua e Sweet Crew.

Nosso intuito com este zine foi o de criar dispositivos que possam ampliar os índices de transversalidade nos movimentos e coletivos protagonizados pelos jovens. A transversalidade, conforme formulada por Guattari (1981), diz respeito à abertura comunicacional intra e inter grupal para além dos níveis verticais e horizontais de comunicação e que pode ampliar o compartilhamento das experiências dos jovens. Nossa aposta ética é que a produção de saber possa fortalecer espaços de participação que interroguem certo discurso hegemônico que privilegia as carências e supostas delinquências dos jovens de periferia, negligenciando suas experiências minoritárias e suas apostas em criar coletivamente redes quentes de afirmação da vida. Produzir, fortalecer e expandir conexões é o que fundamenta ética e politicamente as intervenções que efetuamos. Redes quentes que operam a favor dos processos de diferenciação e fortalecendo a produção de novas formas de existência que possam resistir aos regimes de opressão e submissão (BENEVIDES et al., 2005).

Muitos de nós têm apontado nos últimos 6 anos, com certa insistência, a intensificação dos processos de regulamentação da vida no contemporâneo, boa parte destes processos sendo efetuados por meio de políticas estatais de saúde, educação e assistência social, dentre outras. Uma biopolítica da existência vai se forjando, criando a cada dia novos perigos. Não nos esqueçamos dos apontamentos de Foucault (2008), indicando que o nascimento dos Estados Modernos é contemporâneo ao nascimento da biopolítica. E que o liberalismo sempre primou por efetuar uma gestão das liberdades. A inserção nas políticas sociais tem engendrado modos de vida de forma a intensificar a 
produtividade do vivo. Uma espécie de empreendedorismo social vai se alastrando e se infiltrando entre nós, de forma muitas vezes sutil. As novas sobrevivências dos mais pobres precisam ser objeto de ação deles mesmos. Assim vai sendo forjado um empreendedorismo protagonista que, consumindo a potência de criação do vivo, coloca esta potência para trabalhar e agir a serviço de mais subserviência e dominação. Assim, a inserção de coletivos de juventude em programas governamentais, a participação destes em editais governamentais, em programas governamentais voltados à juventude, tem de algum modo delineado modos de expressão de juventude, modulado estas existências.

Estes mecanismos de regulamentação estão voltados para certos grupos sociais, mais especificamente para parcelas de alguns grupos. Para aqueles que de algum modo não conseguiram se alinhar a certas iscas de 'inclusão social' restaria o lugar de matáveis. Não podemos esquecer que, mesmo com as políticas afirmativas criadas nos últimos 10 anos, serão apenas alguns sujeitos dentre os pobres, dentre os negros pobres, que conseguirão tomar parte nestas políticas sociais, aqueles que mais se aproximem de certos modos de vida. Outros figurarão como aqueles corpos passíveis de criminalização, de violência, de extermínio, os corpos que Mbembe (2018) analisa ao falar do funcionamento necropolítico do capitalismo.

Não podemos esquecer que é próprio do funcionamento biopolítico fazer viver e deixar morrer, e que a violência é um dispositivo de regulação e controle populacional. A violência não é um acidente, ela é um dispositivo fundamental do funcionamento biopolítico contemporâneo. Portanto, não é à toa que o percentual de jovens assassinados pela polícia e pelas milícias só vem progredindo nos últimos anos e que, dentre estes, o maior percentual de mortos é o de jovens negros e pobres. Uma segmentarização se efetua entre aqueles que serão incluídos no acesso aos bens de consumo, movimentando a roda neoliberal da economia, e aqueles outros passíveis de extermínio ou de uma vida sucateada nas terceirizações, porque na roda do capital não cabem todos. É em nome da segurança que as vidas destes sujeitos se tornam um alvo cada vez mais crescente, seja para modular suas existências, seja para deixá-las morrer. Há corpos que são matáveis, há existências que não importam!

Neste cenário de regulamentação da vida, o acesso às políticas governamentais tem sido tomado ora como possibilidade de reverter o processo de sucateamento da existência, sobretudo dos mais pobres, ora tem se mostrado como dispositivos de controle a céu aberto. Controle que define não apenas quem pode passar nas portas de entrada dos 
178 Ana Lucia Coelho Heckert; Caíco Barbosa da Costa; Daniel Barros Bermudes; Isabelle Emerick da Rocha; Joyce dos Anjos Barcellos; Kaick Rocha Pereira; Leonardo Martins Roriz Rébuli; Mariana Ribeiro de Souza; Raiani Dercilia da Silva; Thamires Lemos Ferreira.

programas de saúde, educação e assistência social, mas que se volta também às portas de saída destas mesmas políticas. Ou seja, o bom trabalhador, o bom pobre, o bom usuário da saúde e da assistência social. O bom usuário seria aquele que rapidamente deixa de ser usuário (SANTOS et al., 2017).

Na última década proliferaram pelo país os chamados coletivos de juventude. Segundo os próprios participantes, um coletivo é uma grupalidade. Os coletivos de juventude têm delineado formas organizativas que se diferenciam de formas clássicas de organização política. A atuação destes se dirige às questões do cotidiano, sendo que a maior parte destes grupos tem uma atuação na chamada esfera cultural. A maioria destes coletivos emerge em periferias e este modo de organização da juventude expressa outros modos de pensar e fazer política. É expressão dos exercícios de resistência dos jovens da periferia, ainda que os dispositivos de poder tentem capturar as forças vivas de resistência. Sua forma de funcionamento é horizontalizada e reúne, em sua maioria, jovens moradores ou ex-moradores da periferia, que usam a arte e a cultura como ferramentas de expressão da vida na periferia (LACAZ, 2012).

Uma parte destes coletivos está voltada ao embate pelo acesso às políticas públicas. Outra parte não se envolve diretamente com as políticas estatais; ao contrário, mantém com as mesmas uma relação de desconfiança e descrédito. E há ainda grupos que estão vinculados a programas governamentais e mantêm com o Estado uma relação estreita, sendo o aparelho estatal responsável pela sobrevivência ou não destes coletivos. Neste último grupo, os editais são, por excelência, a forma de sobrevivência, além dos projetos sociais implementados por ONGs e OSCIPs. Este é um dos fios da navalha, pois os coletivos de juventude vêm assegurando suas ações por meio da participação em editais que perfilam modos de participação, modos de vida; editais que são dispositivos importantes no engendramento de um empreendedorismo social que trata os jovens como capital humano. Os coletivos atuam de modo pontual e tematizam a vida cotidiana na periferia, trazendo para a cena urbana os grafites, a poesia, a literatura, o rap, o funk, o hip-hop, o skate, o cineclube, etc.

O que se vive hoje é uma atroz intolerância a todo e qualquer movimento que expresse de forma clara que a vida é incerta e varia sempre. Uma intolerância racista e homofóbica à alteridade, à incerteza, ao que em mim se diferencia dos parâmetros que costumeiramente teciam minha existência. Intolerância atroz, pois o critério primeiro que 
é a vida tornou-se secundária frente aos valores morais que carregamos. A propriedade, a individualidade, a homogeneidade tornam-se primeiro em relação a uma vida, qualquer que seja ela. Quais modos de vida admitimos como possíveis de serem vividos?

Os fascismos não caem em nossas cabeças por uma mão divina e transcendente. Os fascismos são criações humanas. Nos fascismos, algumas vidas podem ser vividas e devem ser protegidas, outras relegadas à indiferença ou à morte social ou à morte física. Este é o país que tem índices absurdos de morte violenta de mulheres negras, de jovens negros, de indígenas, de pessoas que vivem no campo, de transexuais, de gays, de prostitutas. A onda conservadora que vivemos tem como efeito o fomento do ódio ao que difere, ódio ao diverso, ódio ao que desestabiliza as permanências de minha vida.

Os coletivos, as ocupações das escolas, os cursinhos populares, são novas formas de participação nas políticas públicas; diríamos que são formas diretas de participação. São expressão de forças instituintes e de muitos intoleráveis gritando à nossa porta e nos dizendo que não é mais possível aceitar como naturais e necessárias certas práticas. Uma invenção de outros modos de resistência passa a brotar no asfalto seco e quente.

Nos sinais da rua há cantos disformes que entoam proposições que podem ressoar e contaminar. No lugar do confinamento asséptico, tais proposições nos convidam às misturas fortalecedoras de práticas éticas. A memória intensiva das lutas por não obedecer às limitações espaciais e temporais faz ressoar seus gritos e invenções, muitas vezes surpreendendo as análises instituídas referentes às nossas possibilidades de criação (HECKERT, 2014). Muitas de nossas matrizes conceituais dificultam a análise destes movimentos de ruptura, pois partem de procedimentos conceituais e metodológicos que não consideram aqueles movimentos que desobedecem às prescrições e regulações do que vem a ser luta política e movimento organizado. Deste modo, acabam por julgá-los como tentativas incipientes que se perderiam, ou teriam pouca eficácia, por não estarem vinculados, necessariamente, às ações deliberadas e a uma forma de militância programática que deveria ser exercitada no partido político, nos sindicatos e nos movimentos sociais organizados.

Quais ressonâncias esses coletivos provocam? Como assinala Passetti (2017), a arquitetura das revoltas contemporâneas desestabiliza a urbe, inverte enunciados, rompe muros, inventa subjetivações, recusando capturas e pacificações, recusando controles da vida. As revoltas estão a favor dos excessos, não cessam; por isso elas produzem verdades 
180 Ana Lucia Coelho Heckert; Caíco Barbosa da Costa; Daniel Barros Bermudes; Isabelle Emerick da Rocha; Joyce dos Anjos Barcellos; Kaick Rocha Pereira; Leonardo Martins Roriz Rébuli; Mariana Ribeiro de Souza; Raiani Dercilia da Silva; Thamires Lemos Ferreira.

possíveis ao quadro atual. Na revolta não cabe a utopia, ela arquiteta heterotopias. Revoltar-se não é útil ou inútil, é da existência libertária da vida, conclui Passetti (2017).

\section{Abrindo picadas, levando solavancos}

Em 2019 definimos pela finalização do Programa de Extensão. A aposentadoria da coordenação do projeto requeria uma decisão e avaliamos que o Programa de Extensão já havia feito inúmeras contribuições e precisava finalizar. Caso contrário, poderíamos cair no risco de arrastar tal ação como um cadáver sem vida, reativando o efeito Mulhmann sinalizado por Lourau (HESS et al., 1993), burocratizando e eternizando um Programa de Extensão que precisa suportar sua finitude. Frente a esta decisão, efetuamos um planejamento de modo a concluir as ações que efetuávamos. Neste processo definimos por acompanhar a reorganização do conselho municipal de juventude de Cariacica, que se encontrava com as atividades suspensas e aguardando ações do governo municipal para sua reativação. Deliberamos também por apoiar as ações do II Ocupa Rede Afirmação na UFES, além de conversar com grupos e entidades para que a reativação do conselho municipal de juventude se desse com a mais ampla participação dos coletivos de juventude e dos grupos, fóruns e entidades que vinham debatendo as questões da juventude no município de Cariacica.

No meio destas ações, fomos surpreendidos com a definição do governo municipal em fazer aliança com o governo federal, apoiando as ações do Programa Em Frente Brasil, que culminaria com a presença da Força Nacional de Segurança em Cariacica/ES. No mês de maio de 2019, já no mandato do atual presidente da república Jair Messias Bolsonaro, o então ministro da Justiça e Segurança, Sérgio Moro, anunciou os cinco municípios que seriam contemplados como experiências piloto do Plano Nacional intitulado Programa "Em Frente, Brasil" (PEFB), abarcando um município de cada região do país, sendo eles: Ananindeua, no Pará; São José dos Pinhais, no Paraná; Paulista, em Pernambuco; Goiânia, única capital, e Cariacica, no Espírito Santo. Os municípios foram selecionados por apresentarem alto índice de homicídios, sendo Cariacica o segundo município do estado do Espírito Santo com o maior número de homicídios dentre os que contam com mais de 100 mil habitantes (IPEA, 2019).

Xeretando os efeitos desta decisão governamental principalmente para os jovens pobres e negros que residem nas periferias, decidimos acompanhar este processo e 
partilhar com grupos, entidades e fóruns nossas preocupações. De início chamava atenção as reduzidas informações sobre o que se passava com a adesão a este Programa Em Frente Brasil. O que se repetia é que esta ação traria mais verbas para investimento em políticas sociais. Em um município que convive com a precarização no acesso a tais políticas, este canto da serpente atrai e, por vezes, apazigua. Nas andanças que efetuamos, fomos nos deparando com uma ausência de informações acerca do que se passava e a reiteração de velhas promessas. Ao mesmo tempo, muitos moradores passavam a aceitar as promessas feitas, pois o convívio com o extermínio dos jovens e a culpabilização de seus modos de vida traz como efeito a crença de que quem não andou corretamente fez por merecer.

A inexistência de informações provocou que uma pequena parte do legislativo do município efetuasse ações, buscando debater os objetivos desta ação e os efeitos que traria ao município. No dia 28 de junho de 2019, foi convocada uma Audiência Pública pelo Vereador de Cariacica, Professor Elinho, com o tema "Os impactos e desafios da Força Nacional em Cariacica". A audiência teve a participação da Secretaria Estadual de Direitos Humanos, dos vereadores do município, dos representantes da Defensoria Pública, dos representantes do Fórum Capixaba de Lutas Sociais e do Círculo Palmarino, e do Subsecretário de integração institucional de segurança do estado para debaterem a escolha do município de Cariacica, os impactos desta escolha, e as ações que almejavam a União e o Estado do Espírito Santo com a operacionalização do referido Plano. Nesta mesma Audiência foi também informado quais seriam os bairros que receberiam a presença da Força Nacional de Segurança, totalizando 28 bairros do município. De acordo com um dos vereadores presentes à sessão que acompanhamos, seria destinado ao município: 100 homens da Força Nacional, 20 viaturas, 100 fuzis e 100 pistolas. Nesta mesma sessão foi proposta e aprovada a criação de uma Comissão Popular de Monitoramento das Ações da Força Nacional de Segurança em Cariacica.

Não integramos a referida comissão, mas participamos de todas as suas reuniões públicas. Assessoramos alguns grupos na elaboração de perguntas que eram destinadas aos agentes governamentais, visando debater e colocar em análise os propósitos deste Programa de Segurança. O acompanhamento desta comissão mostrou que a presença da FSN não havia surtido grandes efeitos naquele momento, se comparado ao índice de violência do último ano, aumentando, inclusive, o número de homicídios no primeiro mês de operação. Na verdade, este Programa governamental colaborava para incrementar o encarceramento de jovens negros da periferia e criminalizar seus modos de vida, 
182 Ana Lucia Coelho Heckert; Caíco Barbosa da Costa; Daniel Barros Bermudes; Isabelle Emerick da Rocha; Joyce dos Anjos Barcellos; Kaick Rocha Pereira; Leonardo Martins Roriz Rébuli; Mariana Ribeiro de Souza; Raiani Dercilia da Silva; Thamires Lemos Ferreira.

acentuando e intensificando as práticas de racismo com que estes grupos sociais lidam diariamente. Na contramão das lutas de muitos movimentos sociais e entidades, que visam diminuir a população carcerária, o governo brasileiro amplia as verbas destinadas à construção de presídios e aumenta o encarceramento em massa de jovens pobres e negros. (DANIN, 2017).

O acompanhamento das ações deste Programa de segurança em Cariacica nos mostrou que questão social cada vez mais é tratada como problema de polícia, de encarceramento, de arma, de controle. E cada vez menos inclui o enfrentamento das variadas formas de exclusão e inclusão que o capitalismo neoliberal fabrica. Reduzir a questão social à criminalidade e à violência, associando pobreza e violência, contribui para manter um Estado de exceção que se justifica em nome da suposta existência de classes perigosas que precisam ser mantidas sob controle. O Programa 'Em frente, Brasil' é uma das expressões do funcionamento necropolítico do aparelho de Estado brasileiro e capixaba. O direito de matar é apresentado e efetuado sob o manto de discursos supostamente apregoadores de cidadania, inclusão, empoderamento, autonomia, protagonismo, etc, para os cidadãos de bem, ordeiros.

Acompanhar estes processos nos mostrou também as lutas que vão brotando no chão deste município, conectando grupos diversos, mostrando que soluções governamentais estão aliadas a este funcionamento necropolítico, em que o Estado é o agente primeiro das ações de violência. No grito dos excluídos, que foi realizado no dia 07 de setembro no município de Cariacica, especialmente em função da presença dos agentes da força nacional de segurança neste território, foi distribuída uma cartilha aos moradores, alertando acerca de como lidar com os procedimentos abusivos das forças policiais. O grito foi encerrado com a leitura de poema de um dos coletivos de jovens de Cariacica.

O percurso deste Programa de Extensão e Pesquisa se encerrou com uma reunião ampliada em que foram convidados alguns aliados que estiveram conosco desde o início das atividades, e os extensionistas que participaram destes 10 anos de atuação. A todos foi entregue um marcador de livro que continha a pergunta ética de Foucault: É inútil revoltar-se?

Do nosso ponto de vista, a potência das lutas por vidas livres e autônomas, ainda que constrangida e neutralizada, jamais é de todo estancada. Essas ocorrências podem nos 
alertar de que a potência constituinte ou os processos de resistência interferem nas ações do Estado, acionando novos problemas e engendrando outras formas de luta por de autonomia. Por isso terminamos com Foucault (2006), com uma citação que nos acompanhou neste percurso de trabalho de extensão e pesquisa. Este autor, ativando em nós a memória intensiva das lutas, e salientando o vigor dos roncos surdos das batalhas, afirmou que

Todas as formas de liberdade adquiridas ou reivindicadas, todos os direitos exercidos, mesmo quando se trata das coisas aparentemente menos importantes, têm ali sem dúvida um último ponto de sustentação, mais sólido e mais próximo do que os "direitos naturais". Se as sociedades se mantêm e vivem, isto é, se os seus poderes não são "absolutamente absolutos", é porque, por trás de todas as aceitações e coerções, mais além das ameaças, violências e persuasões, há a possibilidade desse momento em que nada mais se permuta na vida, em que os poderes nada mais podem e no qual, na presença dos patíbulos e das metralhadoras, os homens se insurgem. (FOUCAULT, 2006: 77).

Nas ações que efetuamos, almejamos exercícios de liberdade que, no viés de Foucault, são o movimento de questionamento das práticas por meio das quais somos constituídos. Uma liberdade que é política, pois faz a análise crítica das subjetivações/objetivações em suas verdades tácitas, possibilitando novas práticas que expandam mundos. Isso requer que nos indaguemos acerca do que estamos fazendo de nós mesmos, da produção de conhecimento e da universidade. Quais mundos queremos habitar? É necessário que nossa produção de conhecimento sirva para esvaziar a força do racismo, a perversidade dos discursos e práticas enaltecedoras da meritocracia, e para tecer vidas mais plenas e audaciosas. Para tecer vidas livres, e não vidas que repetem sem saber o que estão dizendo.

\section{Referências}

BENEVIDES, Regina; PASSOS, Eduardo Henrique Pereira. A humanização como dimensão pública das políticas de saúde. Ciência e Saúde Coletiva (online). 2005, vol.10, n.3, p. 561-571.

BENTO, Maria Aparecida Silva; CARONE, Iray. (Org.). Psicologia social do racismo: estudos sobre branquitude e branqueamento no Brasil. Petrópolis: Vozes, 2002.

COIMBRA, M. C. B.; NASCIMENTO, M. L. Ser jovem, ser pobre é ser perigoso? Revista de Estudios sobre Juventud. Distrito Federal, Ano 9, n. 22, p. 338-355, jan./jun. 2005.

CORDEIRO, Denise. Juventude nas sombras. Rio de Janeiro: Lamparina, 2009.

DANIN, Renata Almeida. A. Loic Wacquant: encarceramento em massa como política social na contemporaneidade. Revista Sem Aspas, Araraquara, v. 6, n. 2, p. 125- 
184 Ana Lucia Coelho Heckert; Caíco Barbosa da Costa; Daniel Barros Bermudes; Isabelle Emerick da Rocha; Joyce dos Anjos Barcellos; Kaick Rocha Pereira; Leonardo Martins Roriz Rébuli; Mariana Ribeiro de Souza; Raiani Dercilia da Silva; Thamires Lemos Ferreira.

133, jul./dez., 2017. eISSN: 2358-4238. Disponível em: https://periodicos.fclar.unesp.br/semaspas/article/viewFile/11162/7205. Acesso em 6 mar. de 2020

DELEUZE, Gilles. Bergsonismo. São Paulo: Editora 34, 1999.

FANON, Frantz. Pele negra, máscara brancas. Salvador: EDUFBA, 2008.

FANON, Frantz. Os condenados da terra. Rio de Janeiro: Civilização Brasileira, 1979.

FOUCAULT, Michel. História da sexualidade 1. A vontade de saber. São Paulo: Paz \& Terra, vol. (1), 2009.

FOUCAULT, Michel. Nascimento da biopolítica. São Paulo: Martins Fontes, 2008.

FOUCAULT, Michel. Microfísica do poder. Rio de Janeiro: Graal, 2007.

FOUCAULT, Michel. "É inútil revoltar-se?" In: FOUCAULT, M. Ética, sexualidade, política. Coleção Ditos e Escritos, volume V. Organização de Manoel Barros da Motta. Rio de Janeiro: Forense Universitária, 2006.

FOUCAULT, Michel. Em defesa da sociedade: curso no Collége de France (1975-1976). São Paulo: Martins Fontes, 2005.

FOUCAULT, Michel. AntiÉdipo: uma Introdução à vida não fascista. In: ESCOBAR, Carlos Henrique (org.). Dossier Deleuze. Rio de Janeiro: Hólon. 1991.

FRAGA, Paulo Cesar Pontes; IULIANELLI, Jorge Atílio Silva. Introdução: juventude, para além de mitos. In: Fraga, P. C. P.; Iulianelli, J. A. S (orgs.). Jovens em tempo real. Rio de Janeiro: DP\&A, 2003. p. 9-16.

GUATTARI, Félix. Transversalidade. In: Revolução Molecular. São Paulo: Brasiliense, 1981.

HECKERT, Ana Lucia Coelho. (2014). Os exercícios de resistência no contemporâneo: entre fabulações e contágios. Psicologia em Estudo, 19(3), Maringá, v.19, n. 3, p. 469-479, set. $2014 . \quad$ Disponível em:< http://www.scielo.br/scielo.php?script=sci_arttext\&pid=S141373722014000300012\&lng=en\&nrm=iso>. Acesso em: 15 fev. 2020

HECKERT, Ana Lucia Coelho, \& PASSOS, Eduardo Henrique Pereira. (2009). Pesquisa-intervenção como método, a formação como intervenção. In Carvalho, S., Ferigato, S., \& Barros, M. E. B. Conexões: saúde coletiva e políticas da subjetividade. São Paulo: Hucitec.

HECKERT, Ana Lucia Coelho. Narrativas de Resistência: educação e políticas. Tese de Doutorado, Programa de Pós-Graduação em Educação, Universidade Federal Fluminense, Niterói, RJ, 2004.

HESS, Rémi; SAVOYE, Antoine. L'analyse instititonnelle. Paris: PUF, 1993.

INSTITUTO BRASILEIRO DE GEOGRAFIA E ESTATÍSTICA. (IBGE) Disponível em: https://cidades.ibge.gov.br/brasil/es/panorama. Acesso em 22/03/2020.

INSTITUTO DE PESQUISA ECONÔMICA APLICADA (IPEA). Atlas da Violência. Rio de Janeiro, 2017. Disponível em: http://ipea.gov.br/atlasviolencia/ . Acesso 12 de jan. 2017. 
INSTITUTO DE PESQUISA ECONÔMICA APLICADA (IPEA). Atlas da violência. Retratos dos Municípios Brasileiros. Rio de Janeiro, RJ, jul. 2019. Disponível em: http://www.ipea.gov.br/atlasviolencia/arquivos/downloads/7047-

190802atlasdaviolencia2019municipios.pdf. Acesso em: 03 mar. 2020.

KASTRUP, Virginia. A psicologia na rede e novos intercessores. In: FONSECA, T.M.G; FRANCISCO, D. (Orgs.) Formas de ser e habitar a contemporaneidade. Porto Alegre: Editora da UFRGS. 2000.

LACAZ, Alessandra Speranza. Pra não dizer que não falei das flores: jovens $e$ resistências no contemporâneo. 2012. Dissertação (Mestrado em Psicologia Institucional) Programa de Pós-Graduação em Psicologia Institucional da Universidade Federal do Espírito Santo, Vitória, 2012.

LOURAU, René. Implicação e sobreimplicação. In: ALTOÉ, S. (Org.). René Lourau: analista institucional em tempo integral. São Paulo: Hucitec, 2004a.

LOURAU, René. O campo socioanalítico. In: ALTOÉ, S. René Lourau: Analista institucional em tempo integral. São Paulo: Hucitec, 2004b.

LOURAU, René. René Lourau na UERJ: análise institucional e prática de pesquisa. Rio de Janeiro: Ed. UERJ, 1993.

MBEMBE, Achille. Necropolítica. Rio de Janeiro: n-1 edições, 2018a.

MBEMBE, Achille. Crítica da Razão Negra. Tradução de Sebastião Nascimento, São Paulo, N-1 Edições, 2018b

NASCIMENTO, Abdias do. O Genocídio Do Negro Brasileiro: processo de um racismo mascarado. São Paulo: Perspectiva, 2017.

OLIVEIRA, Clever Manolo Coimbra de. Atenção Básica na Assistência Social: entre miséria necessária, artes de governar e redes de solidariedade. 2010. Dissertação (Mestrado em Psicologia Institucional) Programa de Pós-Graduação em Psicologia Institucional da Universidade Federal do Espírito Santo, Vitória, 2010.

OLIVEIRA, Fabricio. Relações de poder e modos de (re)existência: Como a juventude negra protagoniza lutas cotidianas contra o racismo em Cariacica/ES? Dissertação (Mestrado em Psicologia Institucional) Programa de Pós-Graduação em Psicologia Institucional da Universidade Federal do Espírito Santo, Vitória, 2019.

OLIVEIRA, Ueber José de; LIRIO, Marcos Marcelo. O projeto escola viva: a política de educação neoliberal de Paulo Hartung, no Espírito Santo (2003-2016). CLIO: Revista de Pesquisa Histórica - CLIO (Recife), n. 35, p. 273-295, Jan-Jun, 2017. Disponível em: https://periodicos.ufpe.br/revistas/revistaclio/article/download/25043/20283. Acesso em 15 de jul. 2019.

PASSETTI, Edson. A arquitetura da revolta. In: RAGO, M.; GALLO, S. Michel Foucault e as insurreições. É inútil revoltar-se? São Paulo: Intermeios, 2017. p. 63-71

PAULON, Simone Mai. A Análise de Implicação como Ferramenta na PesquisaIntervenção. Psicologia \& Sociedade, V. 17, No 3, P. 18-25, Set - Dez, 2005.

ROCHA, Marisa Lopes da; AGUIAR, Katia Faria de. Pesquisa-Intervenção e a Produção de Novas Análises. Psicologia, Ciência e Profissão, V. 23, № 4, P. 64-73, 2003 
186 Ana Lucia Coelho Heckert; Caíco Barbosa da Costa; Daniel Barros Bermudes; Isabelle Emerick da Rocha; Joyce dos Anjos Barcellos; Kaick Rocha Pereira; Leonardo Martins Roriz Rébuli; Mariana Ribeiro de Souza; Raiani Dercilia da Silva; Thamires Lemos Ferreira.

SANTOS, Milton. Por uma outra globalização do pensamento único à consciência universal. 5. ed. Rio de Janeiro: Record, 2001.

SANTOS, Sérgio Pereira dos. Os intrusos e Os outros Quebrando o Aquário e Mudando Os Horizontes: as relações de raça e classe na implementação das cotas sociais no processo seletivo para cursos de graduação da UFES 2006-2012. 2014. 389 f. Tese (Doutorado em Educação) Centro de Educação, Programa de Pósgraduação em Educação, Universidade Federal do Espírito Santo, Vitória, 2014.

SANTOS, Keli Lopes; HECKERT, Ana Lucia Coelho. Problematizando a produção da vulnerabilidade e da pobreza higienizada na Assistência Social. Psicol. teor. prat., São Paulo, v. 19, n. 2, p. 86-97, ago. 2017 . Disponível em <http://pepsic.bvsalud.org/scielo.php?script=sci_arttext\&pid=S1516$36872017000200004 \& \operatorname{lng}=$ pt\&nrm=iso $>\quad$ acessos em 20 abr. 2020. http://dx.doi.org/10.5935/1980-6906/psicologia.v19n2p8697.

SILVA, Marta Zorzal e. Dilemas e Perplexidades do Modelo. In: VASCONCELLOS, J. G. (Org.). Memórias do desenvolvimento. Vitória: Multiplicidade, 2004. p. 59-84.

WAISELFISZ, Julio Jacobo. Mapa da Violência 2013: Homicídios e juventude no Brasil. Rio de Janeiro, Flacso Brasil, 2013.

Ana Lucia Coelho Heckert Professora da Universidade Federal do Espírito Santo E-mail: ana.heckert@gmail.com

Caíco Barbosa da Costa Estudante de Graduação em Psicologia da Universidade Federal do Espírito Santo

Daniel Barros Bermudes Estudante de Graduação em Psicologia da Universidade Federal do Espírito Santo

Isabelle Emerick da Rocha Estudante de Graduação em Psicologia da Universidade Federal do Espírito Santo

Joyce dos Anjos Barcellos Estudante de Graduação em Psicologia da Universidade Federal do Espírito Santo

Kaick Rocha Pereira Estudante de Graduação em Psicologia da Universidade Federal do Espírito Santo

Leonardo Martins Roriz Rébuli Estudante de Graduação em Psicologia da Universidade Federal do Espírito Santo

Mariana Ribeiro de Souza Estudante de Graduação em Psicologia da Universidade Federal do Espírito Santo

Raiani Dercilia da Silva Estudante de Graduação em Psicologia da Universidade Federal do Espírito Santo 
Thamires Lemos Ferreira Estudante de Graduação em Psicologia da Universidade Federal do Espírito Santo

\begin{abstract}
${ }^{1}$ No período de 2014 a 2018, como consequência de um regime de austeridade fiscal adotado pelo governo estadual, foram fechadas 41 escolas estaduais e 6.507 turmas em escolas estaduais. A este respeito, ver Oliveira e Lirio (2017).

${ }^{2}$ Os mestrandos responsáveis por este debate eram, respectivamente, Clever Manolo de Oliveira e Cleilson Teobaldo dos Reis, ambos naquela ocasião com experiência profissional na área da assistência social. As graduandas em psicologia que participaram da criação do Programa de extensão eram: Ellen Horato Pimentel, Giselly Ferreira Martins, Renata Junger, Rafaela Amorim, Keli Lopes Silva, Camila Detoni e Kesya de Souza Silva. O psicólogo Clever Manolo de Oliveira assumiu a coordenação técnica do projeto de extensão junto com a docente da universidade.
\end{abstract}

${ }^{3}$ A respeito da pesquisa intervenção, recomendamos os artigos de Paulon (2005) e de Rocha e Aguiar (2003).

${ }^{4} \mathrm{O}$ campo de intervenção refere-se ao espaço-tempo acessível aos responsáveis pela ação em função de uma encomenda que dispara a intervenção; inclui ainda as mudanças operadas neste espaço-tempo em virtude da análise da encomenda que disparou a intervenção. Já o campo de análise é constituído pelas ferramentas conceituais utilizadas no processo de intervenção (HECKERT; PASSOS, 2009).

${ }^{5}$ Acerca da noção memória intensiva e extensiva, ver Heckert (2004).

${ }^{6}$ Implicação e sobreimplicação são formulações elaboradas no campo da análise institucional e enunciadas por Lourau (2004a).

7 A respeito da Rede Afirmação indicamos a página do grupo em uma rede social: https://www.facebook.com/redeafirmacao/? $\mathrm{rdc}=1 \& \mathrm{rdr}$

${ }^{8}$ Fazemos aqui referência a Rodrigo Jesus e Quitéria do coletivo Poesia no Busão, que nos ajudaram neste processo com os coletivos e a produção de zine.

${ }^{9} \mathrm{O}$ zine pode ser acessado em http://proex.ufes.br/publicacoes-de-projetos-de-extensao. 